\section{POST MYOCARDIAL INFARCTION VENTRICULAR SEPTAL RUPTURE AND FACTORS ASSOCIATED WITH ITS MORTALITY: A RETROSPECTIVE STUDY Muhammad Adil', Zohaib Ullah Zahid ${ }^{1 凶}$, Muhammad Saad Jibran', Shahzeb', Muhammad Irfan'}

\section{ABSTRACT}

OBJECTIVES: To determine the incidence of ventricular septal rupture (VSR) following acute myocardial infarction (AMI) and to find out factors associated with its mortality.

METHODS: This retrospective study was done at Lady Reading Hospital, Peshawar, Pakistan in which 03years (January-20I4 to December-2016) data of AMI patients was studied. Patients with VSR after AMI, diagnosed on echocardiography were included. Chi-square test was applied to correlate cardiovascular risk factors and clinical parameters with the mortality in post-MI VSR patients.

RESULTS: A data of 6240 patients with AMI was analyzed in which 60 patients had VSR (incidence rate of $0.96 \%$ ) with $64.7 \%$ having acute anterior MI. It is 8.5 times greater in first-MI and have a delayed onset. Twenty-six patients were excluded due to presence of concomitant complications and rest of 34 were studied in detail. Mean age of post-MI VSR patients was $63.21 \pm 8$.9years, among them $52.9 \%$ were males. Mean time of development of VSR was $4.1 \pm 2.2$ days with the minimum of OIday and maximum of I0days after diagnosis of AMI. Nineteen patients (55.9\%) didn't receive streptokinase. The mortality rate was $38.2 \%$ which was significantly associated with diabetes, tachycardia, shock, high Killip class, renal impairment and multiple VSR's (P-value of $0.012,0.021,0.032$, $0.031,0.036$ and 0.016 respectively).

CONCLUSIONS: VSR incidence after AMI in our study was $0.96 \%$ with 8.5 times greater in first-MI and have a delayed onset. Diabetes mellitus, multiple lesions, presence of shock, tachycardia, renal impairment and high Killip class after development of VSR are associated with high mortality.

KEY WORDS: Ventricular Septal Rupture (MeSH); Myocardial Infarction (MeSH); Mortality (MeSH); Killip class (Non-MeSH); Coronary Artery Disease $(\mathrm{MeSH})$; Streptokinase $(\mathrm{MeSH})$.

THIS ARTICLE MAY BE CITED AS: Adil M, Zahid ZU, Jibran MS, Shahzeb, Irfan M. Post myocardial infarction ventricular septal rupture and factors associated with its mortality: a retrospective study. Khyber Med Univ J 2018; 10(3):154-8.

\section{INTRODUCTION}

Cardic ardiovascular diseases are ranked first for the morbidity and mortality of people world widely.' According to the figures of World Health Organization (WHO), out of the 17.3 million cardiovascular deaths in 2008, heart attacks were responsible for 7.3 million.'The Asian population is more susceptible to myocardial infarction (MI). ${ }^{2,3}$ It has been estimated that $\mathrm{MI}$ is $50 \%$ higher in South Asians than white people of United Kingdom. ${ }^{4}$ Jaffar TH, et al. in 2007 showed that one in four subjects aged $\geq 40$ years may have underlying coronary artery disease (CAD) in urban Pakistan. Jafary $\mathrm{MH}$, et al. in 2007 found $2.5 \%$ mortality after acute $\mathrm{Ml}$ in Pakistan.

One of the deadly complication of acute myocardial infarction is left ventricular free wall/ventricular septal rupture,
I Department of Cardiology, Medical Teaching Institute Lady Reading Hospital, Peshawar, Pakistan

Email ${ }^{\bigotimes}$ : dr.zohaibullahzahid@gmail.com Contact \#: +92-334-90165।I

Date Submitted: December 12, 2017 Date Revised: September 25, 2018 Date Accepted: September 26, 2018

which occurred in 4-24\% in necropsy patients with fatal $\mathrm{MI}$ before the widespread use of cardiac care units. ${ }^{7}$ Among the survivors of acute myocardial infarctions, I-2\% developed this devastating complication in the prethrombolytic era. ${ }^{8-10}$ This incidence has reduced to a figure of $0.4 \%$ in the thrombolytic era as shown by the Global Utilization of Streptokinase and Tissue Plasminogen Activator for Occluded Coronary Arteries (GUSTOI) trial, which studied $4 I, 02$ I patients at 1081 sites in 15 different countries. ${ }^{11,12}$ This is further reduced to $0.17 \%$ in APEX-MI registry, with improvement in pharmaco-invasive therapy being the reason for this drastic reduction. . $^{13,14}$ Similarly, Moreyra AE, et al. in 2010 found incidence of acquired VSR as $0.2 \%$ from Microbial Database for Activated Sludge (MiDAS) database in New Jersey, USA. ${ }^{15}$

It usually occurs in the first week after $\mathrm{MI}$, with a mean time from symptom onset of 3 to 5 days. GUSTO Investigators showed that risk factors most associated with this complication were advanced age, anterior infarction, female sex and no previous smoking."

VSR has extremely poor outcomes, particularly in untreated cases where mortality is 94 percent at 30 days. ${ }^{16}$ The transcatheter closure of post-MI VSR has a success rate of $89 \%$ ( $95 \% \mathrm{Cl} 84 \%$ - $93 \%$ ) as reported by the meta-analysis reported by De Puy, et al. ${ }^{16}$

The aim of this study is to determine the incidence of ventricular septal rupture after acute myocardial infarction and to identify cardiovascular risk factors and clinical parameters with the mortality in these patients once this complication occurred. By determining this information in our region where it is not known till now, we will be able to find out the cases which need early intervention for correction that will definitely reduce the mortality from acquired VSR. 
TABLE I: BASELINE CHARACTERISTICS OF POST MYOCARDIAL INFARCTION VENTRICULAR SEPTAL RUPTURE PATIENTS $(n=34)$

\begin{tabular}{|c|c|c|}
\hline & Mean \pm S.D & Frequency (percentage) \\
\hline \multicolumn{3}{|l|}{ CV Risk Factors } \\
\hline Age (years) & $63.21 \pm 8.9$ & $\begin{array}{ll}-- \\
-1\end{array}$ \\
\hline Gender (male) & --- & $18(52.9 \%)$ \\
\hline Hypertension & --- & $08(23.5 \%)$ \\
\hline Diabetes Mellitus & --- & $12(35.5 \%)$ \\
\hline Smokers & --- & $06(17.6 \%)$ \\
\hline Previous MI & --- & $04(\mathrm{II} .8 \%)$ \\
\hline Family History of CAD & --- & $04(\mathrm{II} .8 \%)$ \\
\hline \multicolumn{3}{|l|}{ Clinical Parameters } \\
\hline Shock & --- & $08(23.5 \%)$ \\
\hline Systolic BP (mmHg) & $92.4 \pm 22.7$ & --- \\
\hline Heart rate (per min) & $82.9 \pm 24.4$ & --- \\
\hline Tachycardia & --- & $08(23.5 \%)$ \\
\hline \multicolumn{3}{|l|}{ Killip class } \\
\hline Class I & --- & $15(44.1 \%)$ \\
\hline Class 2 & --- & $06(17.6 \%)$ \\
\hline Class 3 & --- & $09(26.5 \%)$ \\
\hline Class 4 & --- & $04(\mathrm{II} .8 \%)$ \\
\hline \multicolumn{3}{|l|}{ VSR characteristics } \\
\hline Time of VSR (days) & $4.1 \pm 2.2$ & --- \\
\hline \multicolumn{3}{|l|}{ Location of $\mathrm{MI}$} \\
\hline Anterior $\mathrm{MI}$ & --- & $22(64.7 \%)$ \\
\hline Non-Anterior $\mathrm{MI}$ & --- & $09(26.5 \%)$ \\
\hline $\begin{array}{l}\text { Ant }+ \text { Inferior } \\
\text { MI }\end{array}$ & --- & $03(8.8 \%)$ \\
\hline \multicolumn{3}{|l|}{ Number of VSR } \\
\hline Single & $\begin{array}{ll}-- \\
\end{array}$ & $14(4 \mid .2 \%)$ \\
\hline Multiple & --- & $20(58.8 \%)$ \\
\hline \multicolumn{3}{|l|}{ Streptokinase } \\
\hline Given & $\begin{array}{ll}-- \\
\end{array}$ & I5 (44.1\%) \\
\hline Not given & --- & $19(55.9 \%)$ \\
\hline Creatinine (mg/dl) & $1.95 \pm 1.9$ & --- \\
\hline Blood sugar (mg/dl) & $198.6 \pm 123.2$ & $\begin{array}{ll}-- \\
\end{array}$ \\
\hline \multicolumn{3}{|l|}{ Outcomes } \\
\hline Discharged/referred & --- & $21(61.8 \%)$ \\
\hline Death & --- & $13(38.2 \%)$ \\
\hline
\end{tabular}

$\mathrm{VSR}=$ ventricular septal rupture; $\mathrm{Ml}=$ myocardial infarction; $\mathrm{BP}=$ blood pressure; $\mathrm{CAD}=$ coronary artery disease; $\mathrm{CV}=$ cardiovascular

\section{METHODS}

This is a retrospective study done at Cardiology department of Lady Reading Hospital, Pakistan. In this study record of 6240 patients with acute Ml admitted over a period of three years between January, 2014 and December, 2016 were analyzed.

Record of included patients was from either gender, having AMI complicated
Record regarding (blood pressure, heart rate and Killip class) and renal profile were recorded at the time of VSR diagnosis.

All cases underwent a comprehensive echocardiography examination that included M-Mode, 2 Dimensional and Doppler (continuous wave and color) with Toshiba machine by an experienced cardiac sonographer at a time of development of acquired VSR. Number and location of defects, direction and severity of shunt and effect of VSR on cardiac chambers sizes and function were studied in detail.

The data was entered into SPSS version 20. Normally distributed continuous variables like age, systolic and diastolic BP, heart rate, creatinine and random blood sugar were expressed as mean \pm standard deviation. Frequency and percentages were used for categorical variables like gender, hypertension (HTN), diabetes mellitus (DM), smoking, previous MI, Killip class, number of VSR and outcome. Correlation of cardiovascular risk factors and different clinical parameters with the mortality was assessed with the chi-square test.

\section{RESULTS}

A total of 6240 patients with acute myocardial infarction data were analyzed in which 60 patients developed ventricular septal rupture. Twenty six patients were excluded due to presence of other concomitant complications (Figure I). It showed an incidence of acquired VSR which is $0.96 \%$, with acute anterior MI having $64.7 \%$ among them.

A data of rest 34 patients was studied in detail. Mean age of post-MI VSR patients was $63.21 \pm 8.9$ years, with $52.9 \%$ were male patients. Mean time of development of VSR was $4 . I \pm 2.2$ days with the minimum of one day and maximum of 10 days after diagnosis of acute MI. Nineteen patients (55.9\%) didn't receive streptokinase (either late for it or there was significant contraindication for it). About 38.2\% of patients of total VSR died. Rest were either discharged on medical therapy or referred for closure. Cardiovascular risk factors and clinical features of these patients are shown in Table I. 
TABLE II: ASSOCIATION OF CARDIOVASCULAR RISK FACTORS AND VARIOUS CLINICAL PARAMETERS WITH MORTALITY IN PATIENTS WHO WERE COMPLICATED WITH VENTRICULAR SEPTAL RUPTURE AFTER ACUTE MYOCARDIAL INFARCTION

\begin{tabular}{|l|c|c|}
\hline \multicolumn{1}{|c|}{ Characteristics } & $\mathbf{X}^{\mathbf{2}}$ & P-value \\
\hline Age Group & 0.389 & 0.533 \\
\hline Gender & 0.389 & 0.533 \\
\hline Hypertension & 0.613 & 0.434 \\
\hline Diabetes Mellitus & 6.35 & 0.012 \\
\hline Smoker & 0.074 & 0.785 \\
\hline Previous MI & 0.266 & 0.606 \\
\hline Family History & 0.266 & 0.606 \\
\hline Shock & 6.4 & 0.032 \\
\hline Tachycardia & 6.2 & 0.021 \\
\hline Killip Class & 5.3 & 0.031 \\
\hline Location of MI & 0.210 & 0.90 \\
\hline Multiple Lesions & 5.78 & 0.016 \\
\hline SK given or not & 1.52 & 0.217 \\
\hline Renal Impairment & 5.1 & 0.036 \\
\hline
\end{tabular}

$\mathrm{MI}=$ Myocardial Infarction; SK=Streptokinase

Table II shows chi-square correlation of different baseline characteristics with the outcomes in post-MI VSR patients. Figure 2 shows mortality in various $\mathrm{CV}$ risk factors and clinical parameter groups. It shows higher mortality in patients with negative history of $\mathrm{CV}$ risk factors except for diabetes, anterior MI, multiple VSRs, no thrombolytics, having shock and renal impairment. Figure 3 shows time of death in these patients after development of VSR. It shows that number of deaths increases with time if patient were not referred for closure.

\section{DISCUSSION}

VSR is one of the rare complications of acute myocardial infarction but carries a very high mortality rate. Its incidence in our study is $0.96 \%$ which is quite lower

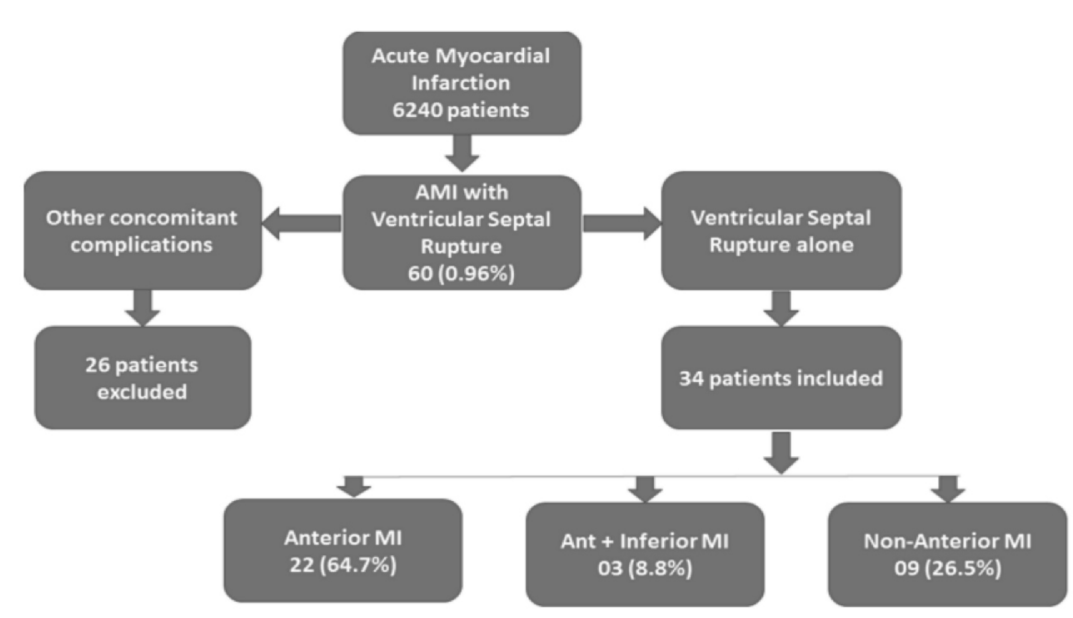

Figure I: Incidence and spectrum of post-MI ventricular septal rupture. correlated with mortality after development of VSR, diabetes, multiple VSR's, tachycardia, shock, higher Killip class and renal impairment was positively correlated with mortality in our study. ${ }^{19}$

Seventy five per cent of patients with Killip class 4 in our study died. A study by Srinivas SK, et al. in 2017 found $20 \%$ and $86.66 \%$ mortality in surgical and medically treated acquired VSR respectively in India. ${ }^{20,21}$ Similarly, Reddy and Robert study suggested 3 times greater development of VSR in first MI compared to those with a previous infarct that healed, but this figure increased to 8.5 times in our study. ${ }^{7}$

It is certainly true that thrombolytics reduced the incidence of VSR development. However, once this complication occur, then history of streptokinase taken is no more significant in determining the outcome of these patients. ${ }^{20,21}$ Late administration of thrombolytic therapy also appears to improve survival but may increase the risk of cardiac rupture. ${ }^{21}$

The limitations of the study are that it is a retrospective study in which data from software were retrieved which had some missing data. Secondly, number of patients with VSR was very small. Third, follow up data of these patients was not available as many survivors of it were referred to other units. Lastly, patients with concomitant presence of other complications like severe mitral regurgitation and heart block patients were also excluded which would have definitely reduced the true mortality from VSR.

\section{CONCLUSIONS}

VSR incidence after AMI in our study was $0.96 \%$ with 8.5 times greater in first-MI and have a delayed onset. Diabetes mellitus, multiple lesions, presence of shock, tachycardia, renal impairment and high Killip class after development of VSR are associated with high mortality.

\section{REFERENCES}

I. Mendis S, Puska P, Norrving B. Global atlas on cardiovascular disease prevention and control. World Health Organization; 201 I. 


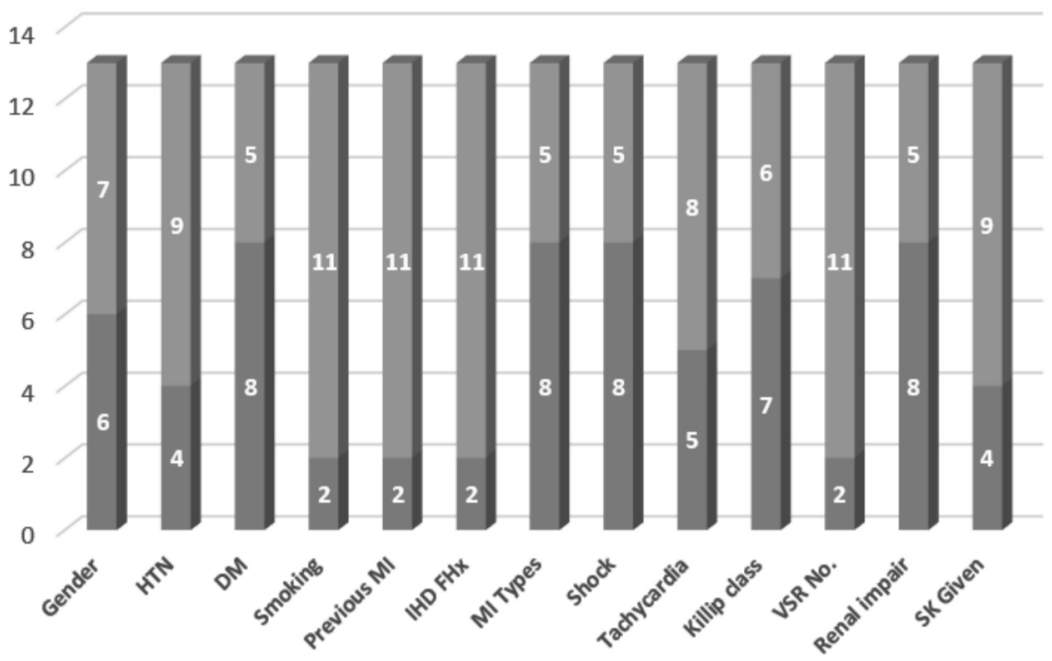

Figure 2: Mortality in various Cardiovascular risk factors and clinical parameters for acquired VSR $(n=13)$. Lower figures represents male gender, Positive History $(\mathrm{Hx})$ [Hypertension (HTN), Diabetes Mellitus (DM), Smoking, Previous MI, Ischemic Heart Disease (IHD) Hx, Shock, Tachycardia, Renal impairment and Streptokinase (SK) given], anterior MI, Killip I-II, and single VSR. Upper figures represents female gender, Negative Hx (HTN, DM, Smoking, Previous MI, IHD Hx, Shock, Tachycardia, Renal impairment, and SK given), non-anterior MI, Killip III-IV and multiple VSRs.

2. Kearney PM, Whelton M, Reynolds K, Muntner P, Whelton PK, He J. Global burden of hypertension: analysis of worldwide data. Lancet 2005;365(9455):217-23. DOI: I0.10I6/S0I40-6736(05)I774I-I.

3. Joshi P, Islam S, Pais P, Reddy S, Dorairaj P, Kazmi K, et al. Risk factors for early myocardial infarction in South Asians compared with individuals in other countries. JAMA 2007;297(3):286-94. DOI: 10.100I/jama.297.3.286.

4. Bellary S, O'Hare JP, Raymond NT, Mughal S, Hanif WM, Jones A, et al. Premature cardiovascular events and mortality in south Asians with type 2 diabetes in the United Kingdom Asian Diabetes Study - effect of ethnicity on risk. Curr Med Res Opin 2010;26(8): 1873-9. DOI: I0.II85/03007995.2010.490468.

5. Jafar $\mathrm{TH}$, Qadri Z, Chaturvedi N. Coronary artery disease epidemic in Pakistan: more electrocardiographic evidence of ischaemia in women than in men. Heart 2008;94(4):408-13. DOI: I0.I | 36/hrt.2007.120774.

6. Jafary $M H$, Samad A, Ishaq $M$, Jawaid SA, Ahmad M, Vohra EA. Profile of acute myocardial infarction (AMI) in
Pakistan. Pak J Med Sci 2007;23(4):485-9.

7. Reddy SG, Roberts WC. Frequency of rupture of the left ventricular free wall or ventricular septum among necropsy cases of fatal acute myocardial infarction since introduction of coronary care units. Am J Cardiol | 989;63(I3):906-II. DOI:
$10.1016 / 0002-9149(89) 90137-9$.

8. Fox $A C$, Glassman E, Isom OW. Surgically remediable complications of myocardial infarction. Prog Cardiovasc Dis 1979;2I(6):46I-84. DOI: 10.1016/0033-0620(79) 90026-4

9. Topaz O, Taylor AL. Interventricular septal rupture complicating acute myocardial infarction: from pathophysiologic features to the role of invasive and noninvasive diagnostic modalities in current management. Am J Med 1992;93(6):683-8. DOI: 10.1016/0002-9343(92)90203-N.

10. Heitmiller R, Jacobs ML, Daggett WM. Surgical management of postinfarction ventricular septal rupture. Ann Thorac Surg | 986;4I(6):683-9I. DOI: I0.1016/S0003-4975(I0)63093-7.

I I. GUSTO Investigators. An international randomized trial comparing four thrombolytic strategies for acute myocardial infarction. N EngI J Med 1993;329(10):673-82. DOI: I0.1056/NEJMI9930902329|00I.

12. GUSTO Angiographic Investigators. The effects of tissue plasminogen activator, streptokinase, or both on coronary-artery patency, ventricular function, and survival after acute

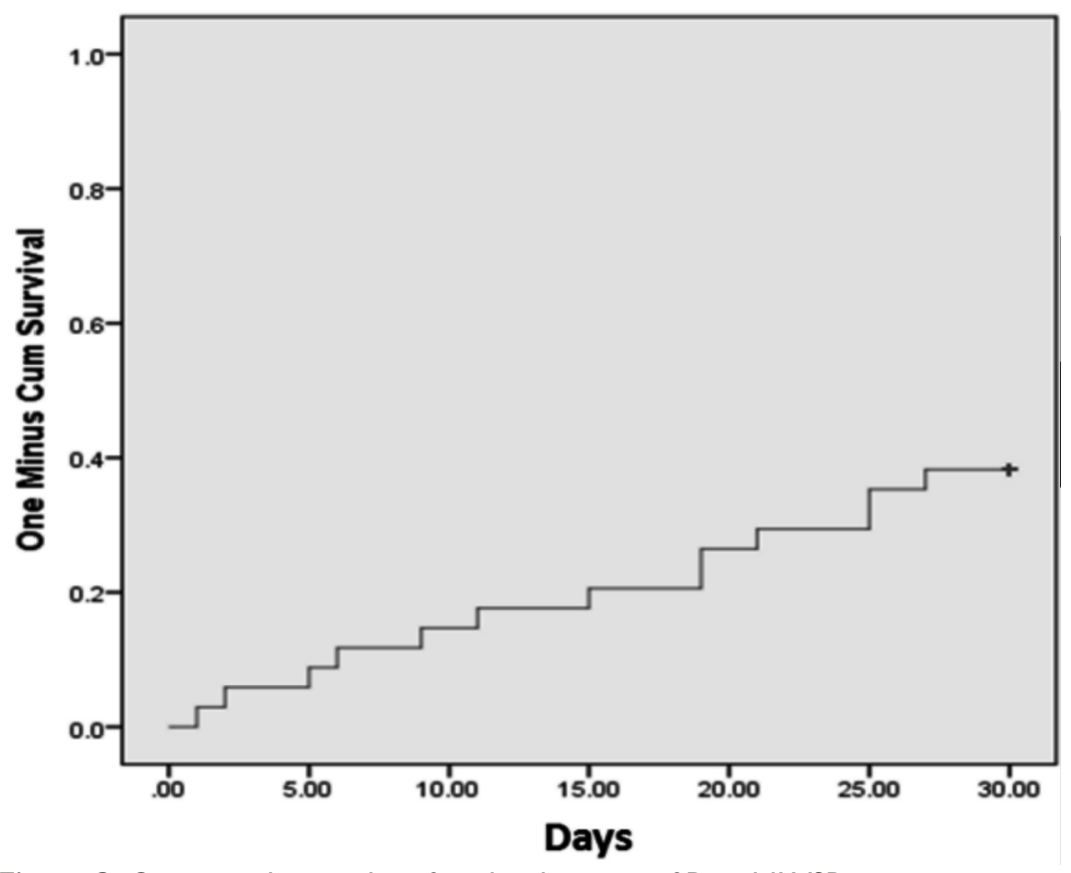

Figure 3: One month mortality after development of Post-MI VSR 
myocardial infarction. N Engl J Med 1993;329(22): I6I5-22. DOI: I0.1056/NEJMI 993 I I 253292204.

13. Rao DS, Patnaik AN, Barik R, Nemani L, Prasad AS. Transcatheter closure of postinfarction ventricular septal rupture. J Indian Coll Cardiol $2015 ; 5(3): 220-7$. DOI: 10.1016/j.jicc.2015.03.024.

14. Tang L, Fang Z, Hu X, Tang J, Shen $X$, Lu $X$, et al. Non-surgical repair of ventricular septal rupture after acute myocardial infarction. Int J Cardiol 20I5; I85:328-32. DOI: 10.1016/j.ijcard.2015.03.144.

I5. Moreyra AE, Huang MS, Wilson AC, Deng Y, Cosgrove NM, Kostis JB, et al. Trends in incidence and mortality rates of ventricular septal rupture during acute myocardial infarction. AmJ Cardiol 20 I0; 106(8): I095-I I00. DOI: I0.1016/j.amjcard.2010.06.013

16. De Puy FG. Outcomes of percu- taneous repair of postinfarction ventricular septal rupture in acute myocardial infarction: a metaanalysis. J Am Coll Cardiol 20I5;65:(10 Supp):AI856. DOI: 10.1016/S0735-1097(I5)61856-3.

17. Becker RC, Charlesworth A, Wilcox RG, Hampton J, Skene A, Gore JM, et al. Cardiac rupture associated with thrombolytic therapy: impact of time to treatment in the Late Assessment of Thrombolytic Efficacy (LATE) study. J Am Coll Cardiol 1995;25(5): 1063-8. DOI: 10.1016/0735-1097(94)00524-T.

18. Becker RC, Gore JM, Lambrew C, Weaver WD, Rubinson RM, French $W$, et al. A composite view of cardiac rupture in the United States National Registry of Myocardial Infarction. J Am Coll Cardiol 1996;27(6): I32I-6. DOI: 10.1016/0735-1097(96)00008-3.

19. Crenshaw BS, Granger $C B$,
Birnbaum Y, Pieper KS, Morris DC, Kleiman NS, et al. Risk factors, angiographic patterns, and outcomes in patients with ventricular septal defect complicating acute myocardial infarction. GUSTO-I (Global Utilization of Streptokinase and TPA for Occluded Coronary Arteries) Trial Investigators. Circulation 2000; IOI (I):27-32. DOI: I0.II6I/0I.CIR.I0I.I.27

20. Srinivas SK, Sunil B, Bhat P, Manjunath $\mathrm{CN}$. Effect of thrombolytic therapy on the patterns of post myocardial infarction ventricular septal rupture. Indian Heart J 2017;69(5):628-33. DOI: I0.1016/j.ihj.2017.03.007.

2I. Honan MB, Harrell FE, Reimer KA, Califf RM, Mark DB, Pryor DB, et al. Cardiac rupture, mortality and the timing of thrombolytic therapy: a meta-analysis. J Am Coll Cardiol 1990; I6(2):359-67. DOI: I0.1016/0735-1097(90)90586-E.

\section{AUTHORS' CONTRIBUTIONS}

Following authors have made substantial contributions to the manuscript as under:

MA: Concept \& study design, drafting the manuscript, final approval of the version to be published.

ZUZ \& MSJ: Acquisition, analysis \& interpretation of data, final approval of the version to be published.

S \& MI: Critical review, final approval of the version to be published.

Authors agree to be accountable for all aspects of the work in ensuring that questions related to the accuracy or integrity of any part of the work are appropriately investigated and resolved.

CONFLICT OF INTEREST

Authors declared no conflict of interest

GRANT SUPPORT AND FINANCIAL DISCLOSURE

NIL

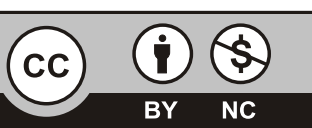

This is an Open Access article distributed under the terms of the Creative Commons Attribution-NonCommercial 2.0 Generic License.
KMUJ web address: www.kmuj.kmu.edu.pk

Email address: kmuj@kmu.edu.pk 